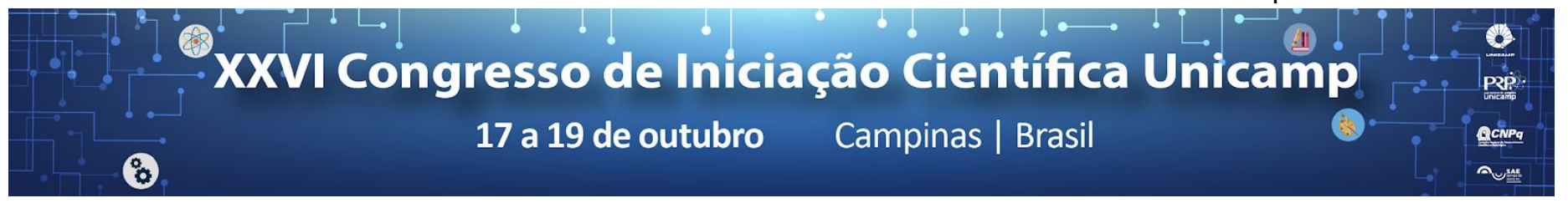

\title{
Condições climáticas e produção da agricultura familiar no semiárido baiano
}

\section{Juliana Daikawa*, Alexandre G. Maia}

\section{Resumo}

Realização de interpolação através do metodo Inverso da Distância Ponderado (IDW) para um banco de dados referentes as estações hidrometeorológicas de séries históricas até 2015, com valores diários disponíveis, obtidos através do portal HIDROWEB da Agência Nacional de Águas (ANA).

\section{Palavras-chave:}

Agricultura familiar, mudanças climáticas, semiárido

\section{Introdução}

Este projeto de iniciação científica enquadra-se em uma pesquisa mais ampla aplicada na região semiárida baiana, e que tem como objetivo central a avaliação dos impactos econômicos do sistema produtivo MAIS proposto pelo projeto Adapta Sertão, identificando as soluções tecnológicas e o arranjo produtivo integrado que mostrem o possível caminho da resiliência climática do produtor familiar do semiárido brasileiro. Os objetivos centrais foram:

a) a caracterização pluviométrica e fluviométrica do Brasil;

b) elaboração de funções sobre dados hidrometeorológicos;

c) interpolação de valores das estações em objeto grid pelo método IDW (Inverso da Distância Ponderado).

\section{Resultados e Discussão}

Na primeira parte do projeto, foi estruturado um banco de dados referentes as estações hidrometeorológicas de séries históricas até 2015 , com valores diários disponíveis, obtidos através do portal HIDROWEB da Agência Nacional de Águas (ANA).

Primeiramente, foi preciso juntar o banco de dados para conseguir o código do município que cada estação pertencia, já que o código oferecido pelo HIDROWEB era diferente do IBGE. Assim, para cada mês de cada ano, o objetivo é pegar a média das variáveis de interesse para cada município.

Neste resumo, o processo será ilustrado com o exemplo de Janeiro de 2017. Neste ano e mês, há valores médios para 1679 municípios. A variável utilizada para a demonstração foi a média da chuva total no mês(Figura 1). Para os 3891 municípios faltantes, seus valores foram obtidos a partir de uma interpolação pelo método IDW $(p=2)$, através da função idw() do pacote gstat do $R$.

Deste modo, juntando ambos os bancos de dados, temos a seguinte representação dos dados de todos os 5570 municípios brasileiros (Figura 2).

No fim, obteve-se uma tabela em que as linhas eram os municípios para cada mês, e nas colunas, as variáveis de interesse, valores reais ou preditos.

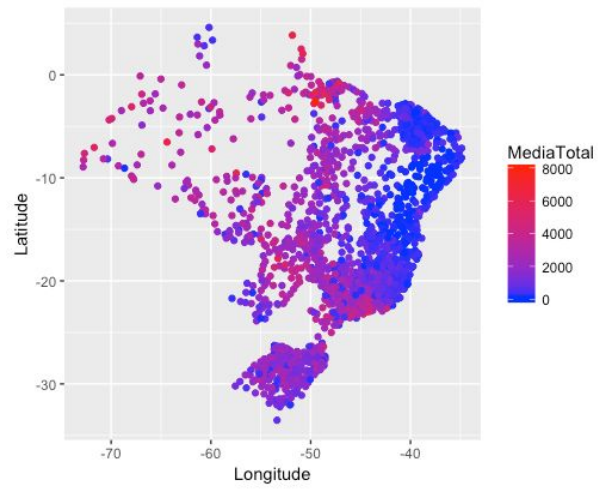

Figura 1. Visualização dos dados disponíveis.

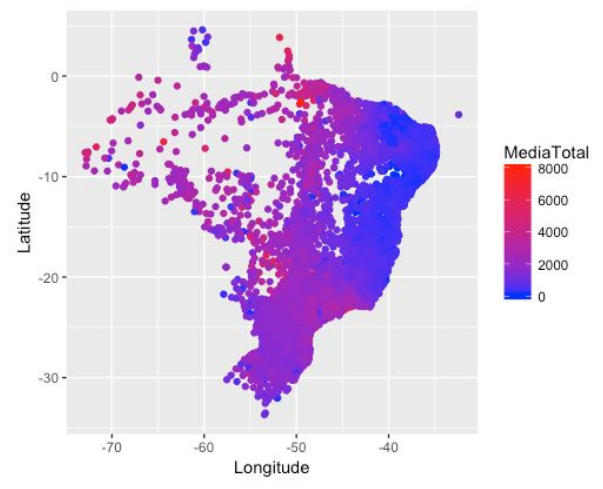

Figura 2. Visualização dos dados finais.

\section{Conclusões}

O método de interpolação IDW permite predizer valores baseada nos valores amostrados à sua volta, sendo que as mais próximas terão um peso maior, do que as mais distantes. Assim, a precisão dos dados varia.

\section{Agradecimentos}

CNPq/Pibic

Serviço de Apoio ao Estudante (SAE)

Fundação CAPES

Instituto de Economia da Unicamp (IE)

https://www.arcgis.com

http://www3.ana.gov.br 